\title{
Effect of Insider Trading on Market Efficiency
}

\author{
Sultan Mehmood Muhammad Shaoor Ul Hassan Muhammad Irfan \\ Riphah International University
}

\begin{abstract}
The research has basically determined relationship between insider trading and its significant effect on market efficiency based on different informational levels. Various insider data was adopted specifically from Swedish market regarding stock prices, capitalization of market, and GDP as well. The main focus of the study was to address how informationally advantaged and disadvantaged insiders impact allocation of information in the stock prices. In this way, various theories and models were also studied to measure its impact on Swedish market. Since the research gathered empirical data, it has only focused on certain companies in varying sizes in the period of 2003 to 2017. Along with this, different statistical tests were also performed to ensure that assumed facts and scenarios have certain relevancy with the literature and past concepts. From the results, it was found that there is a negative effect of insider purchasing on firms' informational efficiency whereas positive effect of insider selling. It is concluded that when fair dealing is done in the markets, traders are expected to perform efficiently.
\end{abstract}

DOI: $10.7176 /$ RJFA/11-24-03

Publication date: December $31^{\text {st }} 2020$

\section{Introduction}

There is always a need for traders to remain active on the market so that they can trust the prices upon which specific actions are taken. In this regard, market itself has to develop efficient pricing strategies on securities. Practically, markets that are efficient in holding prices are capable to endure intrinsic values in which both security prices and value are of same worth. The studies have suggested numerous measures for market to place major emphasis on efficient pricing among which effective information for traders has been considered vital. This is because when traders incorporate more information in each price, efficient in securities are more sustained. The following research investigates impact of insider trading on market efficiency, which will lead to overcome gaps in the research, thesis question, and purpose as well.

\section{Background Problem}

Many past researches have examined efficiency of markets at broader level. In this way, different theories were also developed to understand the importance of market efficiency and role of insider traders in incorporating best practices to hold prices. According to the theory of Farma Ng, Wang, \& Wang (2016), there are some relevant prerequisites that are needed to hold efficiency of the market. It has determined three different levels of market efficiency that ultimately reflects the strength of the efficiency. However, Farma's theory by disregarding these levels suggested that when market is efficient, there are more chances for it to price securities at intrinsic value. From this perspective, it is ensured that buyer can simply trust the prices that are presented to him and thus, these prices are correctly subjected to certain security. In this way, the consequence of efficient pricing often leads to nominal returns that are made by the trader, despite it is undergoing process of buying and selling.

Apart from this, there is a possibility that market returns might differ between securities; explanation behind such differences remain natural because there is a leading risk of the security or total cost of the capital. There is still a concern regarding interest based on efficient market with respect to displaying adequate range of prices. This is mainly because there are still some arguments placed for several reasons regarding efficient markets being an integral part of whole economic system. Firstly, concerns regarding credibility and reliability of financial system. This is because all the potential investors are completely dependent on the reliability of financial markets so that they can make effective decisions for buying and selling securities. Nilstoft \& Birgersson (2014) also states that if trust in these markets are not built, there is the possibility that a fewer people will be operating on the market along with less people associated with trade. The consequence is often measured in terms of minimum capital generation, which can be devastating since initial public offering and entering the market is one of the reasons that companies choose of themselves. Similarly, prices held in the market are sometimes not reliable because these prices are not trusted based on their intrinsic value; it is, however, implied when traders decide to buy or sell other securities while they don't find these prices trustworthy and fair.

Practically, financial markets do not perform in the similar way because prices those traders' experiences are the prices that it offers. Majority of the academic researches have examined the extent of reasons that relates to traders' decision and their trust maintained in the market. Among these reasons, it is found that majority of the traders do not trust prices at intrinsic values because they are not aware of the fair dealing and also if the products in the market are being prices at too low or too high. Thus, the concern has become one of the unpleasant situations for the traders since they are always dependent on the system that they cannot trust. Furthermore, traders believe 
that trading must be done upon fair value because it is an important conduct for various shareholders i.e. investors, firm owners, and managerial personnel in the stock market (Berlin \& Johansson, 2017). In addition, when securities are not fairly priced, there is a greater possibility of capital for being misallocated based on macroeconomic perspective (MAZUMDER, 2017). Hence, the following research is developed to focus on the significance of market efficiency and effect of insider trading on the market.

\section{Purpose of Study}

The main purpose of conducting a thorough research on the subject is that it would identify and address any cases that relates to insider trading, which has certain extent of influence on market efficiency and its information. Since the concept is widely experienced in every market across the globe, Swedish market is chosen for critical investigation because it is relevantly covering all aspects that are needed to be examined for the following research. In this way, insider trading activity is highly focused related to the corporation at Stockholm Stock Exchange, which clearly indicates efficiency of the same stock that is currently being observed. Therefore, the study would also explore that whether role of insider trading is effective for achieving informational efficiency of the market or its unregulated activities are linked with creating imperfections that predicts unfair trading patterns in Sweden. Hence, the main motive of the conducting the study is basically revolved around inspecting the primary effects of trading practices and its concepts in developing informational efficiency of the stock markets that also includes size of the corporation and business cycles.

\section{Research Question}

The primary question of the following study is: How insider trading affects informational efficiency of stock market?

\section{Research Gap}

The following study fulfills certain gaps in the existing findings regarding trading patterns and prices in stock that are investigated to be efficient among various countries. Since the research is developed to determine trading and informational efficiency in Sweden, it tends to explore all the financial activities that are subjected to Sweden laws and regulations. Degryse, de Jong, \& Lefebvre (2014) have investigated that Sweden follows specific structure of corporate governance that comply with relevant reporting techniques. In this way, it becomes easy for the researcher to examine trading patterns in the market because it can fulfill criteria of examining levels of efficiency adequately. In addition, Arora, Sharma, \& Vashisth (2017) also examines that shares trading on Stockholm whereas these share prices do not react with the news in Sweden stock market. In this way, there is also an argument based on the insight insider traders already transmit relevant information to the market and thus, companies don't add specific information in their announcements that are needed in trading. These arguments investigates the validity of the assumptions that informational are those insider trades that are practiced in unregulated market while their stock prices are considered efficient if they are not even responsive to the main company announcements.

\section{Literature Review \\ 6.1 Market Efficiency}

There are a number of academic researches in the economic domain, which provides significant knowledge about market efficiency that compares past and present market efficiencies. Most of these researches are developed on Efficient Market Hypothesis (EMH) that is applicable in the real life markets presently. According to Lo (2017), EMH theory explains the process of stock movement and generalizing financial markets as informationally efficient. In addition, it is also explained by Patel, Savani, \& Poriya (2017) that EMH is based on visualizing markets' as informational because they incorporate certain information to the prices of stocks. The theory suggests that all those markets which effectively incorporate information in the stock prices are considered as efficient (Suliman, 2017). Farma, theorist who developed EMH theory, also clarified that there are different levels of strength on the basis of which market efficiency is identified. Hence, there are three significant levels that are further applied to the study including weak, semi-strong, and strong market efficiencies. Among these levels, different factors of information are indicated which supports the strength and also declares the market as efficient. As emphasized by Bahmani-Oskooee et al. (2016), weak level of market efficiency is defined as incorporation of information in the stock prices in the weak-form which is historical prices and is leading to the prices that are held today. In this way, excess returns are not possible from analyzing past prices because the information is already incorporated in the price of the stock. Sen, Singh, \& Mazumder (2017) also relate that concept to the practice that markets are not able to make abnormal returns through the application of technical analysis. The changes are mainly random events on the market and thus, it only follows random behavior as well. Similarly, semi-strong level denotes another practice in the stock market, which refers to inclusion of past prices and other public information in the price of the securities that is effectively done based on experiences and knowledge (Naseer \& 
bin Tariq, 2015). According to Rossi (2015), it is implied that public information is not available that can be used to generate abnormal returns. Different tests are performed to analyze semi-strong efficiency that includes event studies in which analysis of price movement is performed when information is published i.e. annual report publication.

It is evident from the research performed by Arora, Sharma, \& Vashisht (2017) that Swedish market does not come under semi-strong level because external personnel are not able to deduce abnormal returns based on trading patterns followed by the insiders. Another level of EMH theory is based on strong-form, which indicates private information. Omsted \& Olsen (2014) described that strong form is linked with theoretical system that applies the concept of allocating the relevant information about security into the price. It is also perceived that both public and private information is incorporated that is relevant to the securities. Unregulated markets mostly experience strong and efficient informational system because insiders actively act on the information therefore; they tend to incorporate information quickly and efficiently.

There is much theoretical and logical emphasis on EMH, which is also statistically argued because only a few people consider it as true who are able to challenge the market on a regular basis. Based on the survey results performed by MILOŞ \& MILOŞ (2017), only two third of the professionals have followed the principles of the theory during 30 years. This shows that markets are becoming efficient by regulating their strategies and including effective concepts, which increases their potentials and offers variety of insights to the investors to make abnormal returns based on information advantages. Certainly, Fjellestad \& Encinas (2018) elucidates that EMH is only linked to indicating efficiencies whereas it does not provide any explanation regarding investments through which abnormal returns can be made on continuous basis. The fact is considered as logical because both aspects run side by side along with the functions of free markets.

It is also important to understand that market efficiency is also functional on the basis of some conditions that influence prices containing all information to ensure efficiency. According to Chauhan, Chaturvedula, \& Iyer (2014), there are three conditions that support market efficiency and where prices of the securities are considered equal to their intrinsic values. Among these conditions, first is that there can be no transactional cost in trading securities. Second is that no cost must be applicable on the information that is available for market actors. Thirdly, market participants must be aware of the value of the securities and its related information that completely reflects intrinsic value.

\subsection{Insider Trading}

There is certain evidence regarding strong-form efficiency and relationship with insider traders that can earn abnormal returns. According to Chen, Guan, \& Ke (2017), empirical facts emphasize on the abnormal returns that are further linked with the investments of these insiders. However, other researches provide facts and theories that are subjected to oppose other facts at large. The difference in these outcomes generally creates greater understanding of the practice that is linked with insiders and abnormal returns. Hence, it is called that market efficiency differs to the market that is being regarded and thus, it also varies through time. These factors present a relative concept as compared to absolute concepts as proposed by EMH.

Katusiime, Shamsuddin, \& Agbola (2015) have also discussed that there is a greater influence of U.S. senators on both corporate outsiders and insiders in relation with informational advantage. It has used same tests to assess abnormal returns for outsiders, which determined that senators earn abnormal returns in a significant way. However, further test was applied on more than 16,000 common stock transactions that were made by approximately 300 delegates. In addition, the test was also performed on other U.S. house representatives, which concludes that they have tendency to earn abnormal earning regardless of their smaller size. At last, they also included in the explanation that return of a portfolio was measures that mimicked investments of the representatives while also viewed that it only had $6 \%$ of the abnormal returns on the portfolio.

In contrast, there are many other studies as well which do not present positive results in relation with analyzing abnormal returns. According to the study developed by Schønning \& Vatne (2018), performance of insider traders on Oslo Stock Exchange was estimated using various performance measures. The researchers explained that insiders mainly posses' information from time to time since they have not reached the market appropriately and thus, the information are not incorporated in the price of stocks. Their actions on the information are subjected to making money from it if possible. In this regard, insiders tend to buy stocks which are prior to increased abnormal prices while sell these stocks that are prior to declines. By considering the practices illustrated in the study, it is also noticed that most of the earlier research have also supported "buy low and sell high" investment strategy because it helps them in maintaining abnormal returns and market efficiency at large (Tirapat \& Visaltanachoti, 2013).

Information asymmetry theory developed by Akerlof is also linked with understanding implications of information among different actors in the market. According to the theorist, information asymmetry affects the quality of the goods if it is existent in the market. In this way, the buyer is influenced by informational disadvantage as compared to the seller and thus, buyer pays larger amount to check the quality of the good. It is also argued that 
the buyer is often assumed as an informational disadvantage and therefore, it is considered as a significant feature of market interactions. In this way, DeVault (2016) determines that insiders are mainly assumed to have informational advantage as compared to other market actors, which helps in imposing a restriction to trade. Referring to Akerlof's theory, insiders are not restricted by law and thus, they are able to sell bad quality stocks to the market.

There is an argument based on the theory and its application on insiders' practice. According to Parthsarathy (2016), there is a possibility that insiders are informational advantaged and thus, market can be considered efficient in this regard. It is assumed that various market actors spend different amounts of time in gathering specific information so that they can be able to take decisions regarding insider trading and its consequence in receiving valuable information. It is also possible that there can be certain reactions of traders as well without gathering respective information. However, there is another assumption that insiders also provide valuable and fair information to the market which further leads to maintaining market efficiency as there is much information available for traders to lead the market. In such cases, all the actions of the insiders can affect patterns of predictability whereas a random walk would be considered to make market more efficient.

\subsection{Fishman and Hagerty Model}

In order to understand market efficiency and role of insider traders, Fishman and Hagerty Model is used that provides much evidence about the fact that insider trading eventually decreases market efficiency at large (Urquhart \& McGroarty, 2016). However, the most interesting concept in the model is considered that when insiders are present, market is greater in size whereas there is a noticeable decrease in the market efficiency. According to the model, the concept is often practically witnessed because of less number of informed traders in the market. Since insiders are considered to be informational advantage, incentives provided for outsiders to research about the information is highly discouraged. In this way, ordinary traders cannot believe that they can make better money when informed traders are prominent acting in these markets. Thus, the fact is highly related with another argument placed in the model i.e. presence of the informational is not evenly distributed. Thus, it is witnessed that outsiders are mainly hesitant to comply with informed traders which is why trade practice is highly affected. As a result, there will be less competitive market whereas prices will be less efficient as well. Based on the findings of the model, it is also found that professional traders are subjected to more cost to acquire information and thus, it is equivalent to generated return.

\subsection{Effect of Insider Trading on Market Efficiency}

Bügel \& Runge Jørgensen (2019) provides much relevant evidence on insiders and outsiders that are able to make abnormal returns on Swedish market. The research indicated that outsiders have ability to make abnormal returns by mimicking insider investment patterns and therefore, they are able to access public information but it rejects semi-strong form of market efficiency. In this way, it was interesting for the researcher to address practical knowledge and test trading activities along with the effects on the informational efficiency that the companies exhibit during the operations in the same market. Apart from this, there are other studies which indicate that all the traders that have much information as compared to others are also likely to make abnormal returns successfully. However, it is highly argued that when market actors tend to sell overvalued stocks, these are considered as lemons as illustrated in the theory of Akerlof.

It is assumed that when insiders are informationally advantaged then they have greater chances to act on the information and thus, its consequence is measured in terms of inaccurate signals to the market. Thus, there are more chances for the stocks will decrease in value in the future. In this case, it is also likely for the insiders to sell lemons to the outsiders on continuous basis in order to make profits from being informationally advantaged (de Almeida Dourado \& Tabak, 2014). Hence, one of the effects of insider trading on market efficiency is visualized as significant because it can be risky for buyers whereas bad dealings can have bad impression of the market as well. In relation with the theory, there can be different patterns created by such situations in which a noticeable decrease in market's efficiency is evident.

Fishman and Hagerty model further explains that insiders play a vital role in determining efficiency of the market with respect to extent of the information and traders decision. It is argued that when there is high amount of insiders in the market, most of the market actors are reluctant to trade with these actors due to informational advantage being assumed. In this way, the model is highly applicable in the research due to a number of reasons. The assumptions in the model are mainly considered as true because it relates to the fact that insider trading often increases, which decreases market efficiency as a result (Bügel \& Runge Jørgensen, 2019). Practically, the companies in the market comprise of most of the active insider trading and that they would have stocks that make the companies less efficient. When the model is applied to Stockholm, it is believed that it has a fewer incentives to perform analysis on these companies regarding active insiders and therefore, stocks are less efficient as professional traders tend to provide less information.

There is another effect determined from the practical knowledge and thus, it is referred as signaling effect 
which is related to addressing influence on the company and individuals actions that have on the market. It is explored in the study Ek \& Erlinder (2015) that company tends to send signals to the market, mainly by sending new shares or even by increasing the paid out dividends. Similarly, entrepreneurs also send signals to the market, which is related to quality or value of the company. Hence, signaling effect is estimated in terms of insiders to investors acting on the market. Moreover, insiders are also assumed to exhibit superior information as compared to outsiders and therefore, their actions are considered vital. Since the study is based on Swedish market, the signals are interpreted by market on continuous basis. In this way, it is assumed that the information is presented by the authority itself.

\section{Methodology}

\subsection{Philosophy}

Epistemology perturbs about knowledge and regard as what should be concerned as knowledge. An integral fragment that concludes the same proportion which undergoes to assess natural science should equally be acceptable for the social science as well (Mayer, 2015). The theory of knowledge is segmented to two different parts, which further categorized in between the two; they are the polar opposite to each other. One regards as positivism and the other as interpretivism. In accordance to positivism the world has 8 perspective and unique elements, whereas the interpretivistic theory states that the world needs a more sustainable approach rather than depending on just the social science, conceivably with a dash of hermeneutics. Mayer (2015) listed positivism as the direction that proclaim the emulation of natural science is undoubtedly linked with an epistemology stance considering as positivism Fulford \& Hodgson (2016) express a similar notion as considering a positivist, scratch that a sensible positivist, states that the observer is working with a considerable social reality and by the end of it such analysis can be the basis of laws or law like platitude in correspondence to those created by the physical and natural researchers. This indicates that the positivism path to understand the research is with respect to the testing approach. The experimenter does not invent new approaches and theories rather than test subsist for the relevancy and conceivability (Padilla-Díaz, 2015). In this analysis, we will review the internal commerce of the informational efficiency; nevertheless, we are analyzing and working with some mature approaches. We aim to produce an approach that we will overlook through stats and observations, creating an integral part for positivist (Hughes \& Sharrock, 2016). In comparison to synthetic perspective we differ to state our learning by producing fresh hypothesis. The point of difference is the hermeneutic element that we have persuaded some segments in the conceptual structure of ADAPTIVE MARKET HYPOTHESIS (AMH), the shift in the work place has been analyzed, partially because of the behavior stats. Behavior stats are closely link to social science, because the bearing is never reasoned and attainable hence the calculations become dense. This shows that there is a slight chance to sum a theory that is comparative and a greyer version of that the hermeneutics traits (Mayer, 2015).

\subsection{Approach}

As claimed by Teherani et al. (2015) derivable method initiate as an approach that is mature, it's been implemented fervently resulting in a ray of mitigation for new techniques. Alase (2017) enunciate as the evolvement of an approach is put through repeated fervent examinations. It proceeds to state that the action starts with an approach but some states that it begins from the speculations. Considering what is a concord? It is a way for derivable experiment to link to science. A derivable learning infuses the experiment of many speculations. An integral part is describing these theorizing regarding relations to uniting malleable that are added in the investigations (Quinlan et al., 2019). Some trials of these theorizing, altering between receiving and giving equally, puts a quite factual and natural science viewpoints. Similarly, the derivable method is in corresponding to the qualitative method. Because derivable method in corporate experiments with assumptions to seek the link between the malleable. Peering for a link with malleable by secondary data entails quantifiable data. The derivable method consist the discoveries for the end objective. The rationale is to create a new speculation that has never been made before. This deliverable method is conjoined with the qualitative technique as it enables to observe in particular, giving a way to new techniques amidst those discoveries. Moreover, it doesn't entail the end objective with the experiments. The details led out in this analysis are compiled from the mature theories with correspondence to their relevancy in the same genre of probing to be instructed holistically in regards to the thesis report. In addition, implementing the deliverable approach has assimilated the positivistic approach of the world as aforementioned, the perspective of the world through an examiner point of view. An integral segment is the analysis for summing the qualitative data to make a fixation in terms of explaining these theories. Can the participant impact the commerce of informational efficiency? This is the layout of the speculations that will be answered in the thesis report and because of it the proficiency in deliverable method, it is regarded the best choice.

\subsection{Research Design}

The research design is the essential tool elucidates as advice to implement the research design and the survey of ensuring data (Meyers, Gamst, \& Guarino, 2016). The usage of the research design will be utilized as the verifiable 
studies. Verifiable studies are endured as executive testimony and the documents as the authentic statistics (Creswell \& Poth, 2017). Verifiable documents should not be blended with the prerequisite stats. Despite the usage of the material that is summed by other means as secondary data, the verifiable will undergoes thorough research to all the activities and as they are not been summed for the purpose of display materials only (Lewis, 2015). Abdulkadiroğlu et al. (2017) contemplates that the information is utilized; along with the promotion however, they should not be granted as an inadequate subset for acquired stats that the examiner has collected accordingly. We contemplate about the research design that best suits with this analysis. The secondary data is compiled from Finansinspektionen to gain knowledge about the internal commerce. Similarly, for the conventional cost of the organizations we referred from Dannels (2018) to manifest as a specimen. Set aside the emphasis of secondary data and its imminent qualities. Further it is deliberated as the analysis will not be shown as secondary testimonials, the usage was strictly for the activities and no other experimenter summed up the information for this specific cause. Further in this analysis these statics will be applied to answer all the queries regarding this topic on the thesis display.

\section{Results and Analysis}

Insider trade turnover is basically defined as total amount of shares of a company that is traded by insiders in the period of 2003 to 2017 .

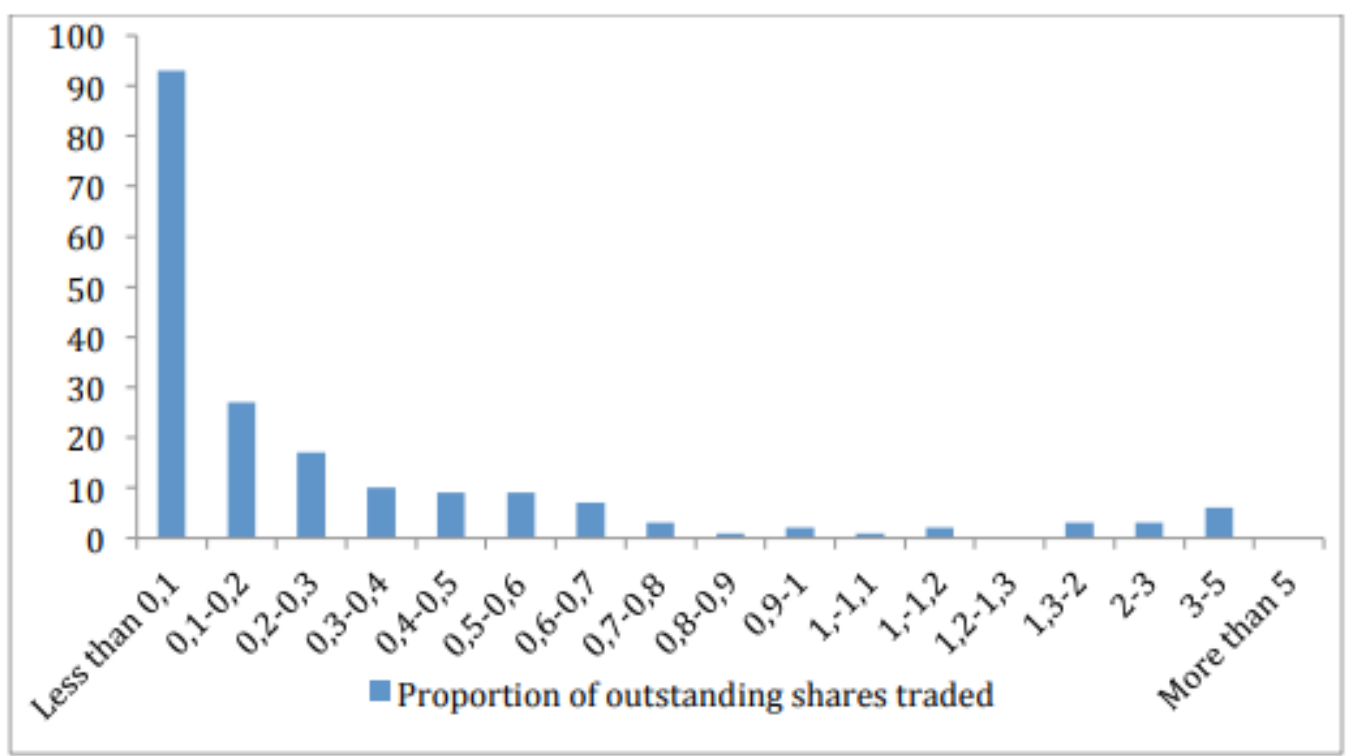

Figure 1 Turnover rate of insider traders

By analyzing figure 1, it can be stated that although certain differences are identified, still, companies in the following study have a turnover estimated as less than $10 \%$. It can be seen from the figure that only a few companies have insiders sold. Majority of the results lie between 0 and 0,1 which is obvious among the corporations. 


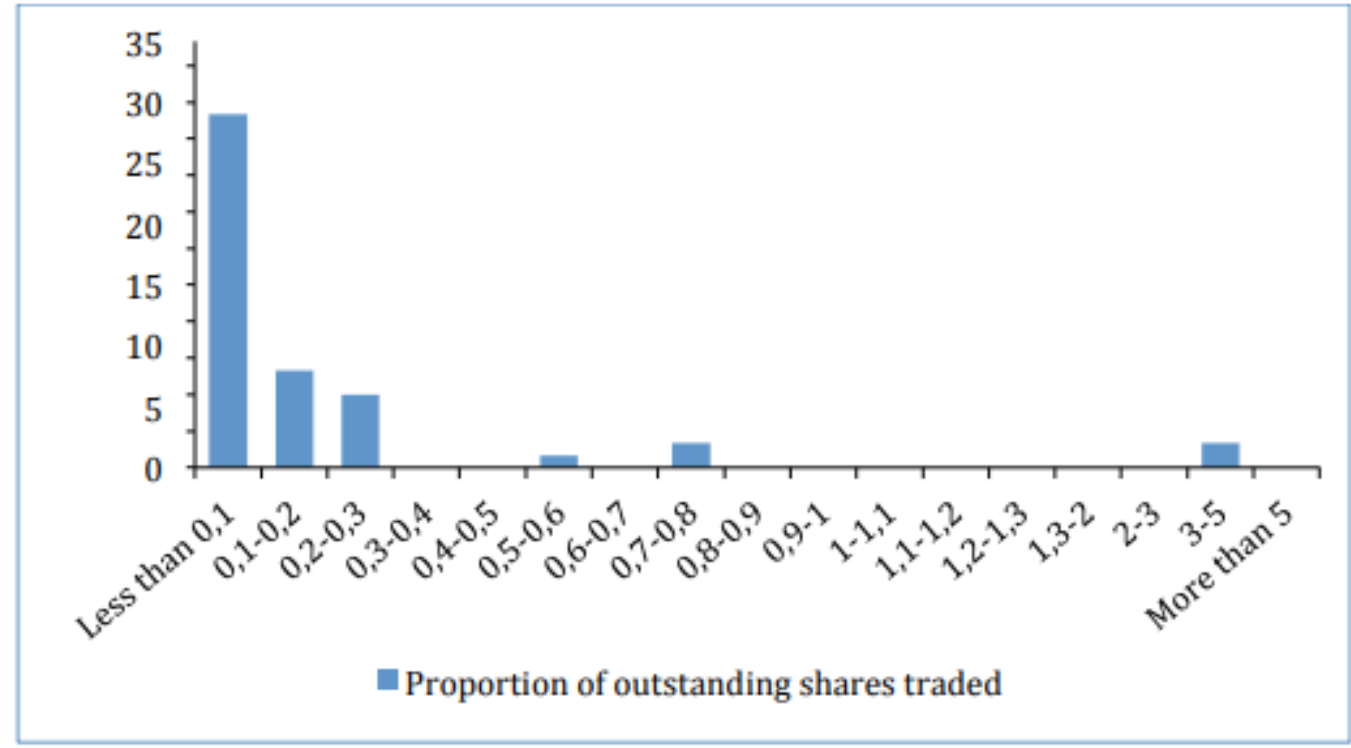

Figure 2 Turnover of Traders in Capt List

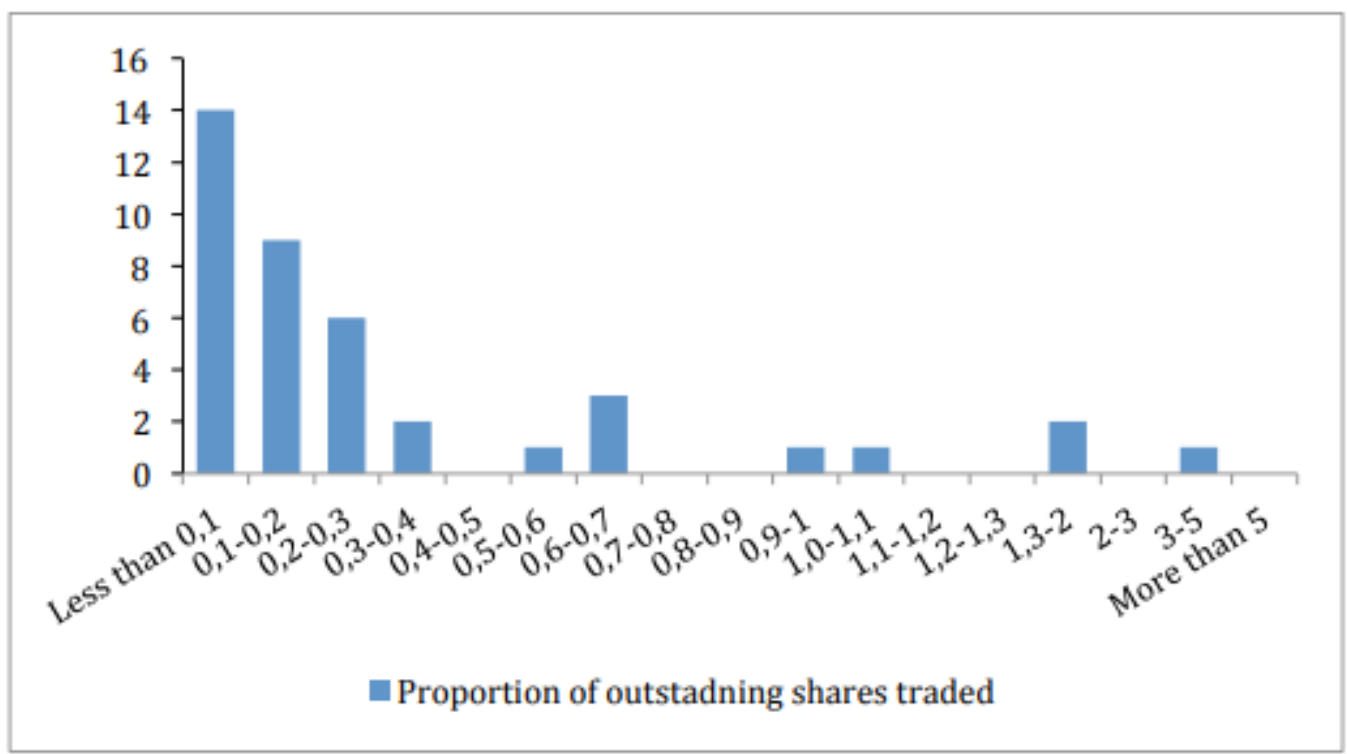

Figure 3 Turnover of Traders in Medium List 


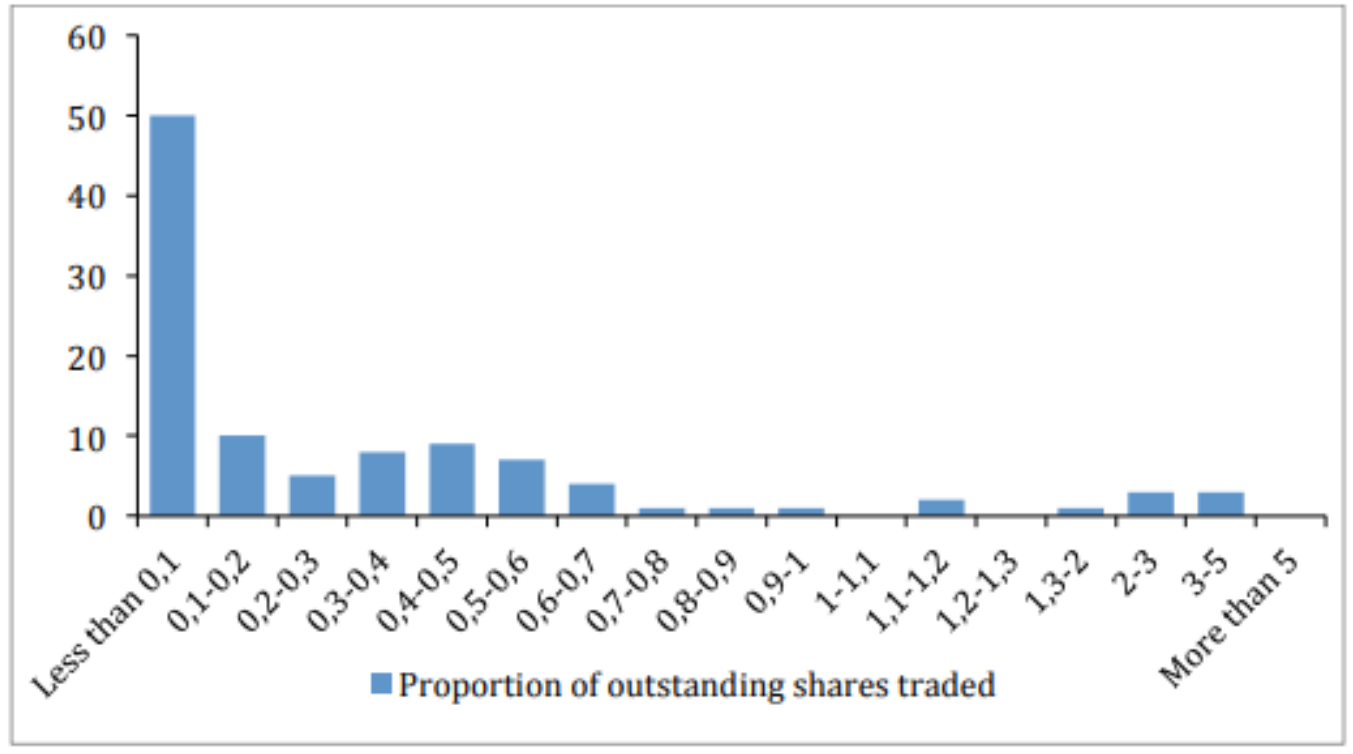

Figure 4 Turnover Traders in Small List

Figure 2 to 4 indicates difference in trading performance with respect to insiders held in different lists. It is can witnessed from these results that turnover rate in Large Cap list is average and least in other two lists. Based on the results in figure 2, insider trade turnover is less than 30\% in Large Cap whereas for small and medium cap list, the trade turnover is evenly distributed and thus, it is estimated to be above $30 \%$. In this way, it is also suspected by the author that insiders find it easy to operate in smaller companies as compared to larger companies.

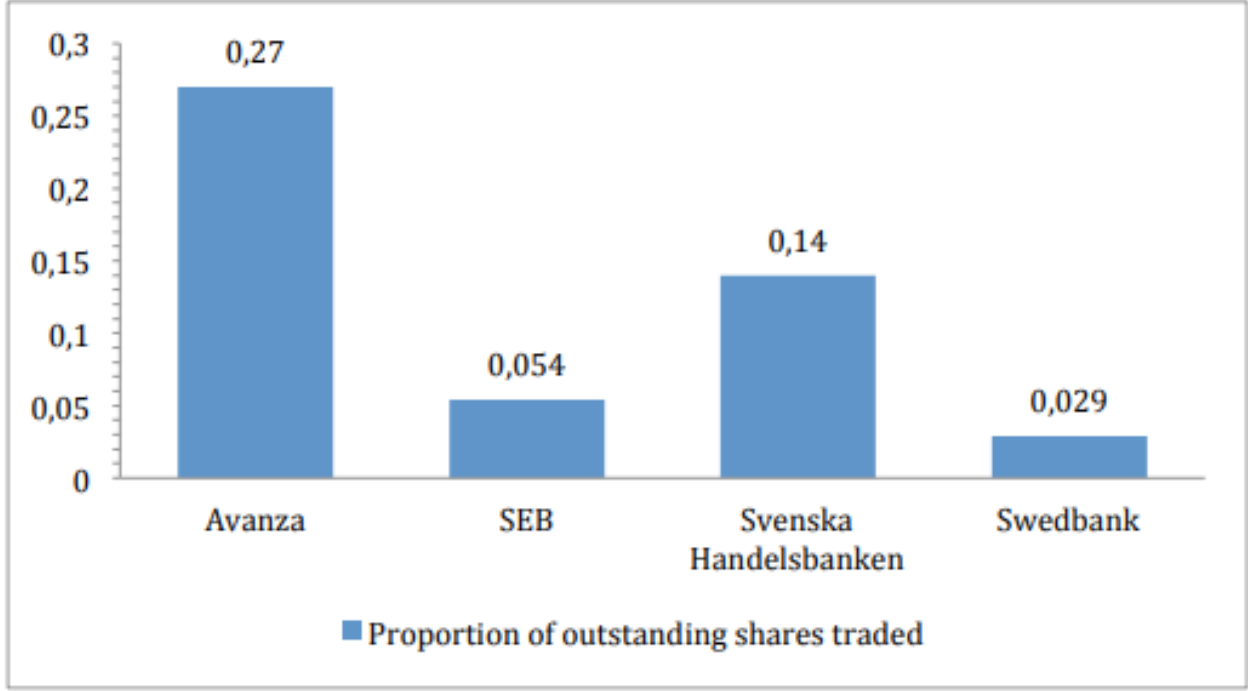

Figure 5 Turnover based on selected banks

Since the study is based on Swedish market, four different Sweden banks were chosen to determine shares in the trade by insiders. From figure 5, it can be seen that $2.9 \%$ of turnover was experienced by Swedbank whereas $14 \%$ of the turnover was experienced by Svenska Handelsbanken bank. In addition, Avanza witnessed the highest turnover, which was approximately $27 \%$ while $5.4 \%$ of the turnover was witnessed by SEB. Although these four banks belong to same industry with same structure, their amount of insider trading differs largely. The main reason behind the difference is suspected to be agency issue, fair structure, and focusing on liberal approach. 


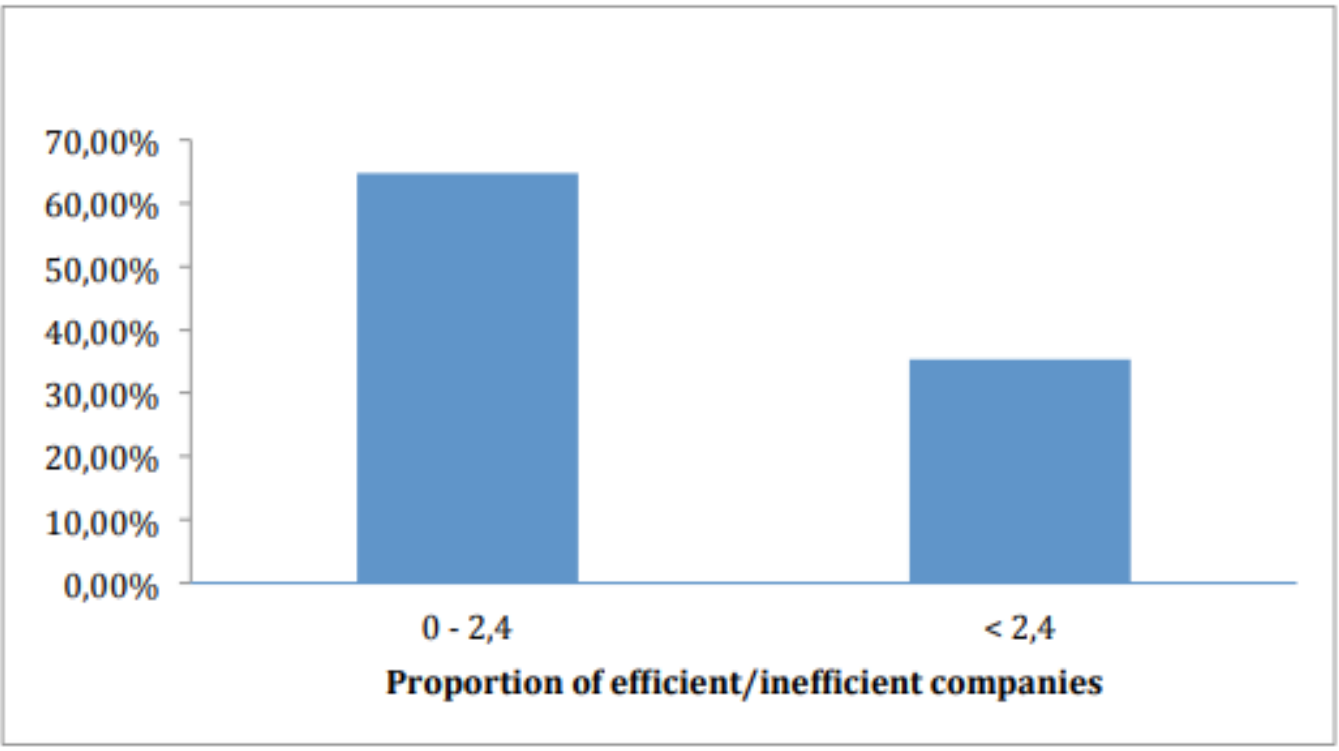

Figure 6 Company-based Efficiency

Market efficiency is deduced on the basis of determining companies' role in trading and thus, results of efficiencies on the basis of companies are also recorded. From the results in figure 6 , it can be seen that approximately $35 \%$ of the companies have values more than 2.4. This ensures that these companies have share prices that are informationally inefficient while gives confidence level of $95 \%$. In this time period, most of the investors are able to make abnormal returns through trading shares and even with technical analysis.

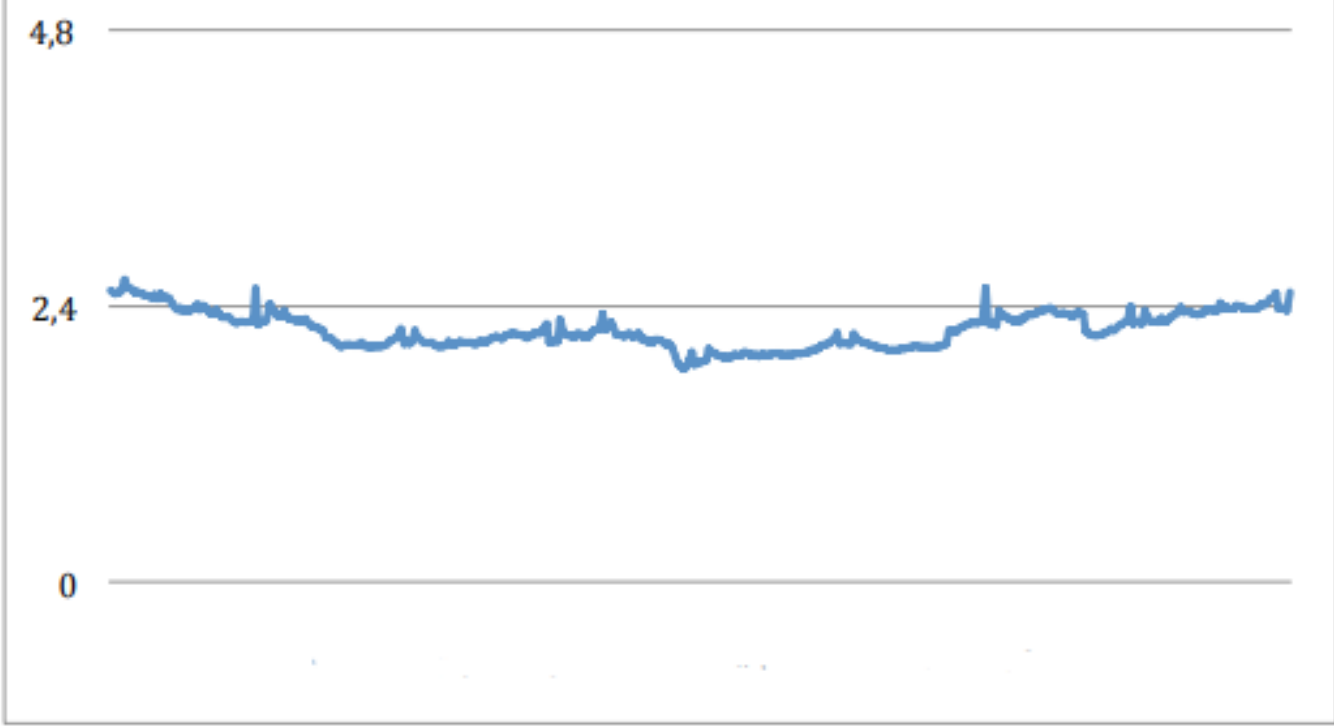

Figure 7 Market Efficiency

Figure 7 describes informational efficiency that fluctuates with respect to time. It involved data and relevant experiences in the firms under investigation. The key to understand the following graph is that if it denotes lower trends, it means there is higher informational efficiency. Hence, it can be seen that market efficiency is indicated high in the middle part of the graph which means that companies were referred to become higher informational efficient. In this way, highest values were identified as 2,634 whereas lowest values were identified as 1,851 . It can be concluded from the results that random walk cannot be rejected.

\section{Discussion}

In order to keep the merchandising place stead fast some rules of internal commerce constitution are essential especially in the places like Sweden and many other regions. If there will be no regulations in terms of businesses people will start making fortunes from the less acquired knowledge of the commoners, however, there will be an impact in the stock cost. In terms like that, the internal commerce will profit by trading immunity long before the yearly paper is issued. Hence, the scripter's realized that Finansinspektionen knows the internal commerce is 
making the merchandising adequate. It is then declared that due to the internal commerce and its strict key components that make the merchandising sufficient and efficacious, and without it can probably make people earn wrong and lucrative money on the overhead of other work agents. This implies the capacity to bear upon the informational boon linked to the analysis of (Boehmer, Fong, \& Wu, 2018). The prerogative states that for efficient merchandizing certain standards must be fulfilled. Enumerating one of the fact that all the specified agents must contain the concerning stats, that was also an incorporated riff in as (Del Guercio, Odders-White, \& Read, 2017). With certain time the Finansinspektionen reached to a closure that meets all the given criteria is precluded. Anyhow if all of the stimulations are fulfilled then there is a good chance that all the viable data for merchandizing along with the cost structure that will help in the boon of agents and their spirit hence, optimizing their business to a new height. However, these idealistic components are rarely ever filled in by the agents as (Bade \& Hirth, 2016). There is an article by Batten, Loncarski, \& Szilagyi (2015) that visualizes a developed and performance oriented along with full flourish merchandizing leading and elevating the cost efficiency. Regardless the matter of Finansinspektionen and their benefactor regulations with the booming of market place is remained ambiguous. The summed up analysis enunciates that the bar of informational efficiency has an impact with the internal commerce constitutions. However the detrimental impact of internal purchasing informational efficiency has a vice versa impact with the selling point of view as it destroys the image of the merchandise. The article Rose \& Søpstad (2015) elucidate the stimulations regarding the impactful internal commerce for the boon of merchandizing. Anghel (2014), though in this article as both of their views contains the contrasting outcomes with the internal existence in merchandizing. The detrimental impact from internal purchasing was distinguished by Smith \& Dyakova (2016) and the internal selling causes the benefits in merchandizing are denoted by (Heymans \& Santana, 2018). If the intention is to produce a set of rules in correspondence to handout the cost efficient stats for merchandizing, allows mitigation in the constitution for the betterment. Set aside a confinement for internal selling and a strict confinement for the internal purchasing, hence suiting the outcome from the compiled analysis rather than the aforementioned rationale. Adopting these mitigations might help them for the bigger cause of merchandizing with optimum privileges. With regards to the analysis report there has been an imbalance in the response of merchandizing to the internal commerce differentiating on the proportions of the organizations. Esen et al. (2019) contemplated an outcome of the bigger masses in merchandising contains much bigger analyst area. Hence, optimize a conclusion that the responses are held dearly on the prompt conveyed from internal organizations, and are deemed as more reactions being sufficed from the agents. Moreover, there are no benefits accustomed with the merchandizing from these responses of internal big businesses, nevertheless creating bad impact on the informational efficiency. The response is however the polar opposite when it comes of medium businesses and the response builds up the informational efficiency for the merchandising. The outcomes designated related to informational efficiency wholly depends on the mitigations applied with accustom to the business size, including the rationale for the constitution to alleviate the level for the informational efficiency. On the basis of the outcome, optimize set of rules should pass in terms of internal commerce for the big businesses. With a notch less restriction for the internal commerce of the medium businesses, considering our result shows that they hold bigger proportions in the informational efficiency.

\section{Conclusion and Implications}

10.1 Conclusion

From the study, it is concluded that it is not imperative to suggest that aggregated results of insider trading is statistically significant based on the informational efficiency. In this way, when insider trading is aggregated into different components, contradicting perspectives can be viewed along with the effects. From the results of the study, it is found that there is a positive impact on informational efficiency by insider selling whereas a negative impact is witnessed by insider purchasing. This ensures that insider selling practices adapt stock prices to its intrinsic value, which is opposite to the insider buying practices. Apart from this, the research has also concluded that there are three different lists that are also affected by insider trading practices in totally different manner. Among these lists, Large Cap list indicates negative relationship among insider purchasing and informational efficiency. When insiders purchase stocks, it means that there is a creation of trends in the stock prices. However, there is a different concept in medium cap list which ensures that selling is significantly highest and thus, there is a strong relationship between selling and informational efficiency. Therefore, it is also perceived that companies that are present in the medium cap list are known to benefit to a great extent from the perspective of insider selling and thus, it contributes to the most in the price discovery process.

\subsection{Theoretical and Practical Implications}

According to the stats of the analysis the internal commerce has no impact on the informational efficiency. Yet, the splitting of the selling and purchasing of the deals are distinguished by the scripter's, albeit they are contrasting. Aforementioned as the selling in terms has a good impact and the purchasing was perceived as the bad impact in the internal commerce of merchandizing. The rationale of this analysis denotes that the optimum internal 
commerce should be debar as an individualistic malleable which shows two elements with separate impacts. These contradicting acts of internal commerce nullify the optimization regarding these malleable. We contemplate the benefaction to explain the internal commerce and its constitutions, regarding informational efficiency. Moreover, the analysis of this thesis report emphasis on the cognizance for depositor affiliating with informational efficiency and internal commerce impact and a holistic approach of the market place for a level head in the sales and business. To generate a better outcome, it is necessary that the depositor has better understanding of the merchandize and the rules to level informational efficiency in the market place. We are optimistic about our thesis report as any bystander with motive to start an effective business can seek guidance from it. Along with pointing a fact that the EFFICIENT MARKET HYPOTHESIS (EMH) approach was vain in regards our analysis report. The report demonstrates the efficiency in merchandising that varies and as time forwards along with new criteria besides techniques infuses will be highly difficult to attain it in the method of EFFICIENT MARKET HYPOTHESIS $(\mathrm{EMH})$. This statement by Finansinspektionen denotes the market efficiency with respect to internal commerce constitution. The query concerning the constitution regards the impact and asked with the Finansinspektionen this deemed with the promised results. The analysis report concludes with the unfavorable impact of the selling and purchasing with the internal features. The constitution should be presented in a way that accelerate the internal commerce and elevate the informational efficiency to reach the top most attainable level. With respect to the selling and purchasing in the internal commerce regarding the level of businesses and thoroughly evaluate in order to boon the market place.

\section{References}

Abdulkadiroğlu, A., Angrist, J. D., Narita, Y., \& Pathak, P. A. (2017). Research design meets market design: Using centralized assignment for impact evaluation. Econometrica, 85(5), 1373-1432.

Alase, A. (2017). The interpretative phenomenological analysis (IPA): A guide to a good qualitative research approach. International Journal of Education and Literacy Studies, 5(2), 9-19.

Anghel, D. G. (2014, September). MARKET EFFICIENCY AND TECHNICAL ANALYSIS IN THE CENTRAL AND EASTERN EUROPEAN REGION. In 7th Annual Conference of the EuroMed Academy of Business.

Arora, S., Sharma, M., \& Vashisht, A. K. (2017). Impact of managerial ability and firm-specific variables on insider's abnormal returns. Decision, 44(4), 275-286.

Arora, S., Sharma, M., \& Vashisth, A. K. (2017). Insider Trading as a Menace: An Indian Perspective. IUP Journal of Applied Economics, 16(4), 7-28.

Bade, M., \& Hirth, H. (2016). Liquidity cost vs. real investment efficiency. Journal of Financial Markets, 28, 7090.

Bahmani-Oskooee, M., Chang, T., Chen, T. H., \& Tzeng, H. W. (2016). Revisiting the efficient market hypothesis in transition countries using quantile unit root test. Economics Bulletin, 36(4), 2171-2182.

Batten, J. A., Loncarski, I., \& Szilagyi, P. G. (2015). Strategic insider trading: Evidence from the foreign exchange markets. Working paper.

Berlin, S., \& Johansson, H. (2017). Insider Trading on Swedish Multilateral Trading Facilities.

Boehmer, E., Fong, K. Y., \& Wu, J. (2018). Algorithmic trading and market quality: International evidence. In AFA 2013 San Diego Meetings Paper.

Bügel, J. S., \& Runge Jørgensen, J. (2019). The Privilege of Possessing Inside Information.

Chauhan, Y., Chaturvedula, C., \& Iyer, V. (2014). Insider Trading, Market Efficiency, and Regulation-A Literature Review. The review of Finance and Banking, 6(1).

Chen, Z., Guan, Y., \& Ke, B. (2017). Should Regulators Ban Insider Trading? Evidence from Hong Kong. Evidence from Hong Kong (June 21, 2017).

Creswell, J. W., \& Poth, C. N. (2017). Qualitative inquiry and research design: Choosing among five approaches. Sage publications.

Dannels, S. A. (2018). Research design. In The reviewer's guide to quantitative methods in the social sciences (pp. 402-416). Routledge.

de Almeida Dourado, G., \& Tabak, B. M. (2014). Testing the Adaptive Markets Hypothesis for Brazil. Brazilian Review of Finance, 12(4), 517-553.

Degryse, H., de Jong, F., \& Lefebvre, J. (2014). An empirical analysis of legal insider trading in the Netherlands. De Economist, 162(1), 71-103.

Del Guercio, D., Odders-White, E. R., \& Ready, M. J. (2017). The deterrent effect of the Securities and Exchange Commission's enforcement intensity on illegal insider trading: Evidence from run-up before news events. The Journal of Law and Economics, 60(2), 269-307.

DeVault, L. (2016). Is' Not-Trading'Informative? Evidence from Corporate Insiders' Portfolios.

Ek, P., \& Erlinder, K. (2015). Insider trading and abnormal return on the Swedish stock market.

Esen, M. F., Singal, M., Kot, H. W., \& Chen, M. H. (2019). Can insider trading in US hospitality firms predict future returns?. International Journal of Hospitality Management, 83, 115-127. 
Fjellestad, M. B., \& Encinas, M. A. (2018). Do Insiders know best?: A study of reported insider trades in the Norwegian and Swedish Stock Market (Master's thesis, Handelshøyskolen BI).

Fulford, A., \& Hodgson, N. (Eds.). (2016). Philosophy and Theory in Educational Research: Writing in the margin. Routledge.

Heymans, A., \& Santana, L. (2018). How efficient is the Johannesburg Stock Exchange really?. South African Journal of Economic and Management Sciences, 21(1), 1-14.

Hughes, J. A., \& Sharrock, W. W. (2016). The philosophy of social research. Routledge.

Katusiime, L., Shamsuddin, A., \& Agbola, F. W. (2015). Foreign exchange market efficiency and profitability of trading rules: Evidence from a developing country. International Review of Economics \& Finance, 35, 315332.

Lewis, S. (2015). Qualitative inquiry and research design: Choosing among five approaches. Health promotion practice, 16(4), 473-475.

Lo, A. W. (2017). Efficient markets hypothesis. The New Palgrave Dictionary of Economics, 1-17.

Mayer, I. (2015). Qualitative research with a focus on qualitative data analysis. International Journal of Sales, Retailing \& Marketing, 4(9), 53-67.

MAZUMDER, S. (2017). A STUDY OF EFFICIENT MARKET HYPOTHESIS AND ITS IMPACT ON VALUATION MODELS IN INDIAN STOCK MARKET, WITH SPECIFIC REFERENCE TO POST LIBERALIZATION PERIOD (Doctoral dissertation, ICFAI UNIVERSITY, JHARKHAND).

Meyers, L. S., Gamst, G., \& Guarino, A. J. (2016). Applied multivariate research: Design and interpretation. Sage publications.

MILOŞ, M. C., \& MILOŞ, L. R. (2017). Regulation, Insider Trading And Stock Market Reaction. What Do We Know?. Annals of'Constantin Brancusi'University of Targu-Jiu. Economy Series.

Naseer, M., \& bin Tariq, Y. (2015). The efficient market hypothesis: A critical review of the literature. IUP Journal of Financial Risk Management, 12(4), 48-63.

Ng, L., Wang, C. X., \& Wang, Q. (2016). Insider Trading, Informativeness, and Price Efficiency Around the World.

Nilstoft, M., \& Birgersson, R. (2014). Is the transparency of the Swedish stock market at risk?.

Omsted, H. S., \& Olsen, J. B. (2014). Estimating the Returns to Insider Trading on Oslo Børs (Doctoral dissertation, Master Thesis. Norwegian School of Economics).

Padilla-Díaz, M. (2015). Phenomenology in educational qualitative research: Philosophy as science or philosophical science. International Journal of Educational Excellence, 1(2), 101-110.

Parthsarathy, S. (2016). Test Of Weak Form Efficiency Of The Emerging Indian Stock Market Using The NonParametric Rank And Sign Variance Ratio Test. Global Journal of Finance and Management, 8(1), 49-64.

Patel, P., Savani, J., \& Poriya, N. (2017). Semi-Strong Form of Market Efficiency for Dividend and Bonus Announcements: An Empirical Study of India Stock Markets. ANVESHAK-International Journal of Management, 6(1), 108-121.

Quinlan, C., Babin, B., Carr, J., \& Griffin, M. (2019). Business research methods. South Western Cengage.

Rose, C., \& Søpstad, N. (2015). Reactions to corporate insider's transactions: Do legal stock market disclosure rules have an impact?. European journal of law and economics, 40(2), 247-272.

Rossi, M. (2015). The efficient market hypothesis and calendar anomalies: a literature review. International Journal of Managerial and Financial Accounting, 7(3-4), 285-296.

Schønning, E., \& Vatne, O. A. Ø. (2018). Does information asymmetry vary between insiders in different industries (Master's thesis, Handelshøyskolen BI).

Sen, S., Singh, B. M., \& Mazumder, S. (2017). Efficient Market Hypothesis: A Study on Indian Capital Market. Research Bulletin, 42(4), 69-79.

Smith, G., \& Dyakova, A. (2016). The relative predictability of stock markets in the Americas. International Journal of Finance \& Economics, 21(2), 131-142.

Suliman, O. (2017). Efficient market hypothesis. The American Middle Class: An Economic Encyclopedia of Progress and Poverty [2 volumes], 70, 126.

Teherani, A., Martimianakis, T., Stenfors-Hayes, T., Wadhwa, A., \& Varpio, L. (2015). Choosing a qualitative research approach. Journal of graduate medical education, 7(4), 669-670.

Tirapat, S., \& Visaltanachoti, N. (2013). Opportunistic insider trading. Pacific-Basin Finance Journal, 21(1), 10461061.

Urquhart, A., \& McGroarty, F. (2016). Are stock markets really efficient? Evidence of the adaptive market hypothesis. International Review of Financial Analysis, 47, 39-49. 